\title{
Exploring the Subtleties of Agency and Indirect Control in Digital Learning Games
}

\author{
Erik Harpstead \\ Carnegie Mellon University \\ 5000 Forbes Ave, Pittsburgh, PA \\ USA \\ harpstead@cmu.edu
}

\author{
J. Elizabeth Richey \\ Carnegie Mellon University \\ 5000 Forbes Ave, Pittsburgh, PA \\ USA \\ jelizabethrichey@cmu.edu
Bruce M. McLaren
Carnegie Mellon University
5000 Forbes Ave, Pittsburgh, PA
USA
bmclaren@cs.cmu.edu

\author{
Huy Nguyen \\ Carnegie Mellon University \\ 5000 Forbes Ave, Pittsburgh, PA \\ USA \\ hn1@andrew.cmu.edu
}

\begin{abstract}
How do the features of a learning environment's user interface impact learners' agency and, further, their learning? We explored this question in the context of Decimal Point, a digital learning game designed to support middle school students in learning decimals. Previous studies of the game showed that giving students the ability to choose the order and number of mini-games to play did not significantly impact their learning outcomes compared to a condition without choice. In this paper we explore whether some elements of the game's interface may have inadvertently exerted indirect control over students' choice, leading to the previous effects. We conducted a classroom study using a new version of the game that varied whether students saw a visual path connecting mini-games on the game map to modulate the level of indirect control students would experience with an implied ordering. Ultimately, we found that students in the no-line condition exercised significantly more agency but did not learn any less than the line condition. These results suggest that indirect control can be a subtle but powerful way to direct student attention in digital learning games.
\end{abstract}

Permission to make digital or hard copies of all or part of this work for personal or classroom use is granted without fee provided that copies are not made or distributed for profit or commercial advantage and that copies bear this notice and the full citation on the first page. Copyrights for components of this work owned by others than the author(s) must be honored. Abstracting with credit is permitted. To copy otherwise, or republish, to post on servers or to redistribute to lists, requires prior specific permission and/or a fee. Request permissions from Permissions@acm.org.

LAK19, March, 2019, Tempe, AZ, USA

(C) 2019 Copyright is held by the owner/author(s). Publication rights licensed to ACM.

ACM 978-1-4503-6256-6/19/03 \$15.00

https://doi.org/10.1145/3303772.3303797

\section{CCS CONCEPTS}

- Applied computing Interactive learning environments • Applied computing Computer games

\section{KEYWORDS}

Digital learning games, agency, indirect control, self-regulated learning

\section{ACM Reference Format:}

E. Harpstead, J. E. Richey, H. Nguyen, and B. M. McLaren. 2018. Exploring the Subtleties of Agency and Indirect Control in Digital Learning Games. In Proceedings of the International Conference on Learning Analytics and Knowledge (LAK19), March, 2019, Tempe, AZ, USA. ACM, New York, NY, USA. 9 pages. https://doi.org/10.1145/3303772.3303797

\section{INTRODUCTION}

Allowing people to exercise their agency by making choices in learning environments and games is regarded as important for both learning [37] and engagement [31]. At the same time there remains some debate about whether providing learners choice leads to pedagogical benefits. For example, young learners can have difficulty in making effective instructional choices [24], often making unthoughtful or even random choices [36].

Within the context of digital learning games, the issue of agency has been explored in two recent studies. Sawyer et al. [32] studied three different versions of the game Crystal Island: a high-agency condition where students had the freedom to explore the game world and choose which activities to do and in what order, a lowagency condition where students did the activities but had to follow a fixed order, and a no-agency condition where they had no control over the game at all, merely watching a video. The result of the study was that students in the low-agency condition demonstrated the greatest learning gains, suggesting that at least some degree of 
agency is beneficial to learning, but providing students with too much choice may reduce their learning.

In an alternate study of student agency Nguyen et al. [26] employed a similar manipulation of problem selection within the game Decimal Point. In their study, students in the high-agency condition could play a series of mini-games in any order they chose while students in the low-agency condition could only play the next mini-game within a prescribed order. Students in the high-agency condition also had the options to stop playing halfway through the game or play an extra round of mini-games, while students in the low-agency condition had to complete all of the mini-games, with no option to stop or play more. Contrary to Sawyer et al., they found no significant difference in learning between the conditions.

While the results of these two investigations would seem to suggest a contradiction, post-hoc analysis reported by Nguyen et al. [26] suggests another alternative. In looking at how students approached the game they found that while students in the highagency condition had the option to play mini-games in any order and stop before completing them all, more than 20 percent of students followed the exact sequence of mini-games as the students in the low-agency condition and almost 70 percent played the same number of mini-games. One reason they suggest for this is that the design of the game's map strongly implied a prescribed order and may have exerted some indirect control over the students by providing visual cues about the path they should follow, in particular, a line between mini-games that suggested order of play [34]. Given this possible confound, the question of whether learning is enhanced through choice over problem sequencing in digital learning games remains open.

In this paper we explore this question further by performing an expanded replication of the Nguyen et al. study. In particular, we compared three versions of Decimal Point, two based on the conditions of the original study and a third that changed the game map to remove the implied ordering and thus reduce the sense of indirect control. Constraint through choices is another form of indirect control. In the Nguyen et al. study, students were allowed to stop playing after finishing half of the mini-games, but they were not given as clear a mechanism to express the choice to quit or keep playing once they reached the midpoint. Given the large number of students who played all of the mini-games despite being able to quit early, we added reminders in the high-agency conditions to make sure students realized when they had the choice to quit playing.

Our research questions and hypotheses are as follows:

RQ1: How does the inclusion of indirect control impact students' exercise of agency in a digital learning game? While the phenomenon of indirect control in games has seen less formal study, existing examples [33] suggest that removing elements of indirect control will lead to increased exercise of student agency.

RQ2: How does the inclusion of indirect control impact learning and enjoyment? Following the logic of indirect control as a potential reason for Nguyen et al.'s null effect with regard to learning, we would expect that including indirect control would lead to no effect on learning, while removing it may negatively impact learning, though it could increase enjoyment.

RQ3: How does the exercise of agency in different contexts impact learning and enjoyment? Given the conflicting prior results of Sawyer et al. [32] and Nguyen et al. [18], it is difficult to hypothesize what the effect of exercising agency will have on learning and enjoyment. However, as our study uses the same game as Nguyen et al. the result of no effect is generally more likely.

\section{Agency}

Several researchers have studied agency, autonomy and motivation in the past. In this section we discuss the related theoretical perspectives that contextualize our work.

Although it is often believed that the provision of choices leads to higher agency and learning, research in this area, especially in the context of digital learning games, has produced mixed results. While a number of studies have shown students' learning outcomes improve when they are given control over instructionally irrelevant components of the learning experience [5, 37], others that have looked at broader categories of choices, including instructionally relevant ones, reported no difference between choice and no-choice conditions $[6,29]$. In some cases, students who were given limited choices achieved greater learning gains than those with more choices $[10,32]$. In explaining these contrasting findings, a metareview by Patall, Cooper, and Robinson [27] pointed out that the effect of choices largely depends on both internal factors, such as type of choice and number of options, and external factors, such as reward, control condition and individual characteristics.

From a cognitive perspective it might seem that giving learners more instructional choices could also increase working memory demands, diverting cognitive resources away from the intrinsic load of the actual learning tasks by instead focusing them on potentially extraneous choices [39]. Prior research in this area has shown that giving learners more control does not seem to increase cognitive load, and in some cases may even reduce it $[15,35,40]$. Another cognitive consequence of choice concerns the degree to which students need structure to make appropriate learning decisions. Learners who lack sufficient knowledge may not be able to identify an appropriate order or strategy for completing learning materials on their own [17]. As a result, if there is an ideal order or path for completing materials, agency may reduce learning by giving students the opportunity to study in unproductive or less optimal ways.

Beyond the cognitive consequences of choice, there has also been work looking at the affective impacts of choice. Two important components in the relationship between choice and learning are topic interest and situational interest [1]. Topic interest indicates the student's inherent interest in the content of material and is often stable and content-specific. Situational interest, on the other hand, is spontaneous and triggered by environment stimuli, such as the narrative context or other features of a game. Past studies have shown that topic interest and situational interest are positively correlated [11], and that situational interest, rather than choices, is the primary motivator, having strong effects on learning, engagement and attitude [12]. 
Exploring the Subtleties of Agency and Indirect Control in Digital Learning Games

From the perspective of self-determination theory, Reeve et al. [29] conducted a series of studies that showed that internal locus and volition, but not perceived choice, are the best predictors of the experience of self-determination in intrinsic motivation. This suggests that it is less important that students are given choices to make about the task and more important that they feel they are regulating their own behaviors within the task and willingly choosing to engage in the task. In reviewing prior studies, the authors also found that provision of choice only increased motivation when it was also conducive to internal locus and volition. In other words, it is best considered as a contributing element in a larger context, rather than a decisive element. The practical implication is that choices offered to students should be accompanied by other autonomy-supportive features in order to successfully increase self-determination and intrinsic motivation. In prior research, these autonomy-supportive features have taken the form of explaining the rationale of the task and acknowledging the learner's feelings [8]. In the case of Decimal Point, this suggests that students may not experience motivational and learning benefits simply from being given choices about game play, but that they may benefit if they perceive those choices as meaningful to their behavioral regulation and decisions about when and how to engage.

Alternatively, Deterding [9] called to attention the construct of "contextual autonomy," which is often facilitated by, but is not equivalent to, the presence of choices. According to Deterding, autonomy is the feeling of having control over one's actions, but it is also heavily influenced by the situational context of game play. In particular, when students' spontaneous interests and an environment's socio-materially available choices mismatch (e.g., a teacher limiting the modes of a game students can play to specific content), playing can become a controlled experience, which in turn diminishes autonomy. Importantly, effects such as these may not be explicitly or overtly designed into a game and instead may arise from seeming unrelated design choices. The possibility of such indirect control [34] mechanisms is pertinent to our later discussion of Decimal Point.

Wardrip-Fruin and colleagues [41] consider agency in games, beyond learning games specifically, from a lens of player expectations and how they relate to what a player desires both during and after play. While playing, a player only experiences agency when there is a balance between their desires and the game's support for those desires, or, in other words, when the game enables them to take actions that match their desires. External expectations from sources other than the player themselves also play an important role in reducing players' experiences of agency. While games are associated with free and voluntary participation (as is the case of video games), digital learning games are often integrated as part of a school curriculum and thus may impose certain obligations on the participating students. Deterding [9] suggested that these controlling motives could potentially outweigh the game activity's intrinsic need satisfaction, and that solitary leisurely play is the most autonomy-supporting context. However, it is likely to be challenging to develop a digital learning game for this use case, given that the game content (learning materials) may
LAK'19, March 2019, Tempe, Arizona USA

not be appealing to students in their free time. Additionally, while engagement is often one goal for digital learning games, it is typically viewed not as an end itself but a means to the larger goal of learning. This suggests that how students experience agency in a mandatory, in-class digital learning game likely differs in key ways from how players normally experience agency in video games, and it highlights the need for further research investigating both how agency can be supported in digital learning games and how experiences of agency relate to learning outcomes.

\section{Decimal Point}

Decimal Point, depicted in Figure 1, is a single-player digital learning game targeted at middle-school students (ages 10 to 12), helping them learn about decimal numbers and operations with decimal numbers (e.g., adding, ordering, comparing). The game has an amusement park metaphor and is composed of a series of mini-games (e.g., Enter if You Dare, Space Raider, Castle Attack) within the game. Each mini-game targets a specific type of decimal misconception, such as "decimals with more digits are larger" [38].

In the original version of Decimal Point, students play the minigames in a predefined sequence, starting in the Haunted House theme area of the upper left and ending in the Pirate Ship theme area in the lower left. They are guided in the mini-game sequence by a dashed line that runs from top to bottom. This sequence was originally developed both to maintain thematic cohesion and to interleave problem types, which has previously been shown to improve learning from math problems [28, 30]. While the original was intended to support learning, it is unclear whether an optimal path through the game exists. Thus, while students could potentially benefit from customizing the order to focus on problem types that give them the most difficulty, agency in Decimal Point is unlikely to have a negative effect on learning as a result of students deviating from a prescribed, optimal order.

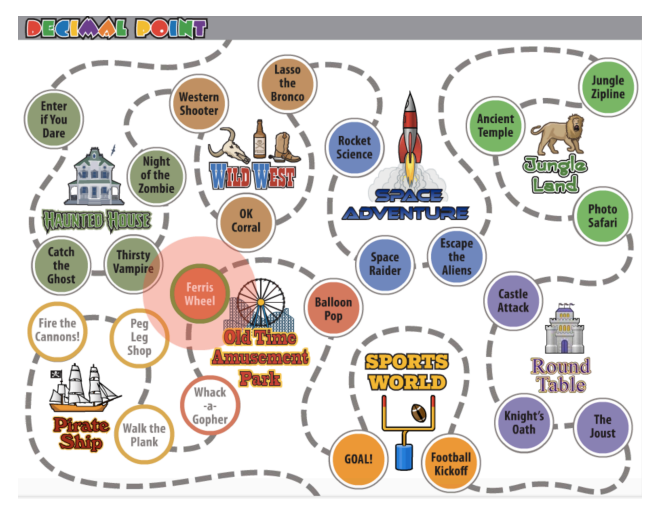

Figure 1. A screenshot of the main map screen of Decimal Point.

Seventy-two decimal problems (three problems for each of the 24 mini-games) have been implemented for the game. Figure 2 shows, respectively, two examples of Decimal Point mini-games: 
Castle Attack and Night of the Zombie. Castle Attack (left) is an example of an ordering mini-game, where students are challenged to shoot targets in a specified order, either smallest to largest decimal or largest to smallest. Night of the Zombie (right), on the other hand, is a number line mini-game, which tasks students with correctly placing a given decimal point on a number line.
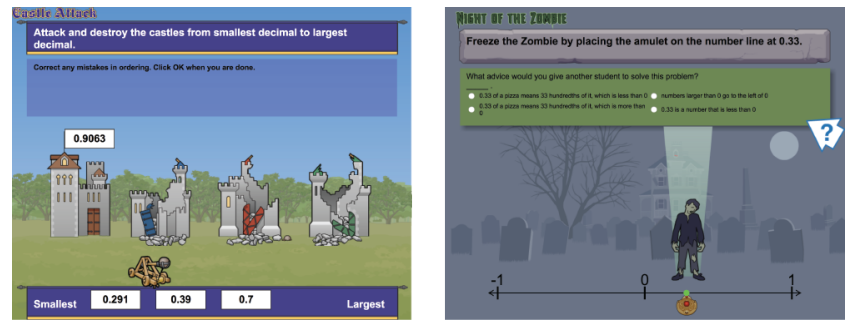

Figure 2. Screenshots of the Castle Attack (left) and Night of the Zombie (right) mini-games from Decimal Point.

In an initial study conducted with Decimal Point [22], a comparison was conducted of middle school students who learned about decimals either by playing the game or working with a comparable, but more traditional, tutoring technology. With over 150 students participating across the two conditions, the game group showed significantly more learning and the game was rated by students as significantly more engaging than the traditional computer-based tutor. Subsequent analyses of this data showed that female students benefited more from the game than male students and the game made difficult problems more tractable, as the game group made significantly fewer errors on the difficult problems than the non-game group [21]. More recently, the game was used to explore student agency, as described earlier in this paper [26].

\section{Method}

We conducted an in-vivo experiment within 3 classrooms in two public schools in a mid-sized U.S. city. The study took place over 6 days during students' regular class time. Each student had five days to complete a self-paced pretest, gameplay, evaluation questionnaire, and immediate posttest. Finally, after one week students took a delayed posttest. Table 1 shows a high-level description of the process.

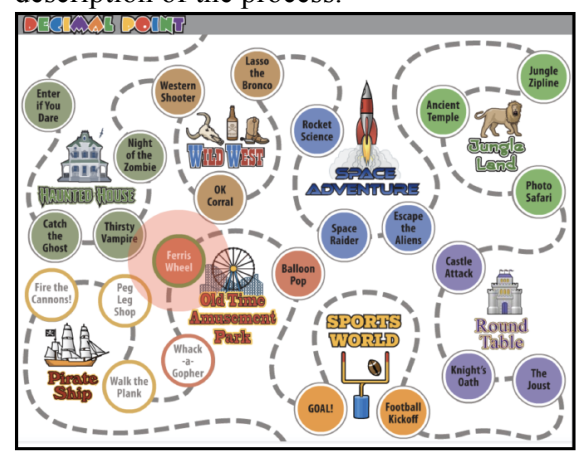

A

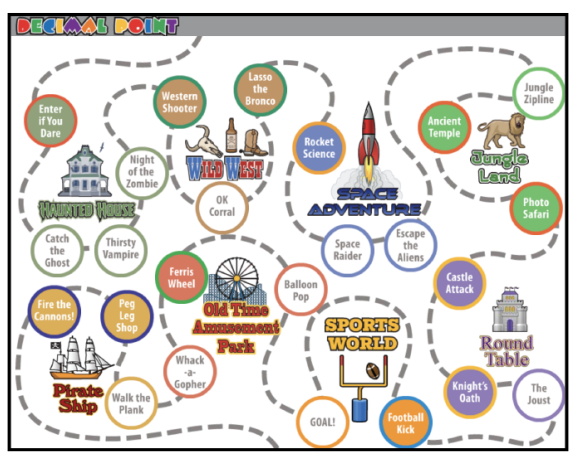

B
A total of 287 students participated in the study. Thirty-five students were eliminated from our analyses because they did not fully complete the materials and tests in the study. An additional 13 students were eliminated because of login errors during at least one of their sessions. Finally, one student was identified as an outlier and eliminated, due to a particularly large total instructional time (using the outlier labeling rule, applied to instructional time and test performance, with 2.2 set as the multiplier, see [16]). Thus, the final sample included 238 students (107 males, 130 females, 1 declined to respond).

\subsection{Materials and Design}

A web-based deployment system was used to present the materials to students [2]. Students were randomly assigned to one of three conditions.

1. Low Agency (LA - 88 students assigned): In the LA group, students played the standard version of the game, depicted in Figure 3A, in which the order of mini-games was pre-defined. Students in this condition had to play two rounds of each minigame (i.e., solving two problems back-to-back during each mini-game), leading to a total of 48 problems solved. This condition is equivalent to the low-agency condition in the Nguyen et al. study [26].

2. High Agency with Line (HAL - 78 students assigned): In the HAL group, students played a revised version of the game, depicted in Figure 3B, in which the students could (a) play the mini-games in any order; (b) stop playing after playing at least one-half of the mini-games, and (c) continue playing more than the standard 48 total mini-games, playing up to one extra round (i.e., one extra problem solved) of each mini-game. The dashboard shown in Figure 4 provided information about the various mini-games, as well as making clear which mini-games had already been played. In this condition students would solve anywhere between 24 and 72 total problems. This condition is equivalent to the high-agency condition in Nguyen et al. [26], but with a reduction in indirect control by reminding students when they could quit playing after the halfway point.

3. High Agency No Line (HANL - 72 students assigned): This condition was equivalent to the HAL condition, in that students could play mini-games in any order, stop player early, and

Figure 3. The different Decimal Point map screens used in the (A) Low Agency, (B) High Agency with Line, and (C) High Agency No Line conditions. Note filled in circles denote completed levels. 
continue playing; but the amusement park map was altered to remove the dashed line path (Figure $3 \mathrm{C}$ ). This was done in an attempt to increase students' sense of agency by removing the indirect control of the implied ordering imposed by the line. Like the HAL condition, indirect control was also reduced in this condition by reminding students when they could quit playing.

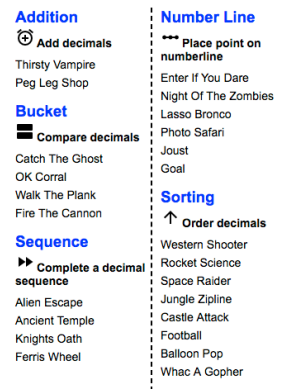

Figure 4. The dashboard shown to students in both of the High Agency conditions showing the mapping between minigames and target skills.

Pretest, Immediate Posttest, and Delayed Posttest. The pretest, immediate posttest, and delayed posttest (conducted one week after the posttest), were administered online in the same online environment as the game. Each test consisted of 24 items, some with multiple parts, comprising a total of 61 possible points. Test scores are reported as the total number of points earned. Test items were designed to probe for specific decimal misconceptions and took a variety of forms, for instance: adding decimal numbers (e.g., $2.41+0.6=\ldots$ ), choosing the next number in a sequence of decimals (e.g., "Write down the next item in the following

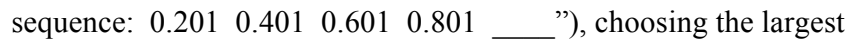
decimal in a given set of decimal numbers (e.g., "Choose the largest of the following three numbers: $5.413,5.75,5.6 ")$, and placing a given decimal number on a number line. There were also conceptual questions, such as "Is a longer decimal number larger than a shorter decimal number? Yes, No, It Depends, Don't Know." There were three test forms (A, B, and C) that were positionally counter-balanced across conditions. One-way analysis of variance (ANOVA) results showed that there was no significant difference in difficulty between the three forms at pretest, $F(2,236)=1.272$, $p=.282$; posttest, $F(2,236)=0.220, p=.803$, or delayed posttest, $F(2,236)=0.339, p=.713$.

Evaluation Questionnaire. After finishing the game, students also filled out an evaluation questionnaire, prompting them to rate their experience. Students could respond on a 5-point Likert scale, ranging from $1=$ "strongly disagree" to $5=$ "strongly agree". For the purpose of our analysis, eight items $(a=.81)$ in the evaluation questionnaire were combined to calculate enjoyment of the game, based on items such as "I liked doing this lesson," "The lesson made me feel that math is fun," and "I liked the way the material was presented on the screen."
Table 1. The overall design of materials used in the three conditions of the study.

\begin{tabular}{|c|c|c|}
\hline LA & HAL & HANL \\
\hline \multicolumn{3}{|c|}{ Pretest (A, B, or C) } \\
\hline \multicolumn{3}{|c|}{ Demographic Questionnaire } \\
\hline $\begin{array}{l}\text { Game Play } \\
\text { (exactly } 48 \text { mini- } \\
\text { games played in } \\
\text { order) }\end{array}$ & $\begin{array}{l}\text { Game Play with } \\
\text { line visible on map } \\
\text { (between } 24 \text { and } \\
72 \text { mini-games in } \\
\text { student chosen } \\
\text { order) }\end{array}$ & $\begin{array}{l}\text { Game Play with } \\
\text { no line visible on } \\
\text { map (between } 24 \\
\text { and } 72 \text { mini-games } \\
\text { in student chosen } \\
\text { order) }\end{array}$ \\
\hline \multicolumn{3}{|c|}{ Evaluation Questionnaire } \\
\hline \multicolumn{3}{|c|}{ Immediate Posttest (A, B, or C) } \\
\hline \multicolumn{3}{|c|}{ Delayed Posttest (A, B, or C) } \\
\hline
\end{tabular}

\section{Results}

To first determine whether students learned from the instructional materials, we collapsed all students across conditions and compared scores across tests. A series of paired-sample t-tests showed significant score increases from pretest $(M=37.92, S D=$ $12.19)$ to posttest $(M=42.62, S D=10.95), t(238)=9.89, p<.001$, $d=0.64$. Scores also increased from pretest to delayed test $(M=$ $43.68, S D=11.11), t(238)=11.82, p<.001, d=0.76$, and from posttest to delayed test, $t(238)=2.84, p=.005, d=0.19$. Having established that students' performance improved after completing the game, we report analyses addressing our three research questions.

How does the inclusion of indirect control impact students' exercise of agency in a digital learning game? To determine whether the indirect control of the map's implied ordering had an impact on how students played the game, we examined the effects of condition on the number of mini-games students played, the amount of time they spent playing mini-games, and the order in which they played the mini-games. Students in the LA condition had no choice about the number of mini-games they played; consequently, standard deviation for mini-games played in the LA condition is 0 and, for this reason, we report Glass' $\Delta$ as a measure of effect size in analyses concerning LA condition [13]. An ANOVA revealed a significant effect of condition on the number of mini-games students played, $F(2,235)=14.34, p<.001, \eta_{p}{ }^{2}=$ .11. Post hoc (Tukey) tests revealed a significant difference between LA $(M=24.0, S D=0)$ and HAL conditions $(M=19.6, S D$ $=5.59), p<.001$, Glass' $\Delta=0.78$, and between LA and HANL conditions $(M=20.0, S D=8.85), p<.001$, Glass' $\Delta=0.45$. There was no difference between the two high-agency conditions (i.e., HAL and HANL), $p=.987, d=0.06$. Thus, students in both the HAL and HANL conditions played significantly fewer mini-games than students in the LA condition.

There was also an effect of condition on how much time students spent playing the mini-games, $F(2,235)=6.41, p=.002$, $\eta_{p}{ }^{2}=.05$. Post hoc (Tukey) tests revealed a significant difference in total time in seconds between LA $(M=2551.96, S D=888.66)$ and HAL conditions $(M=2178.66, S D=939.61), p=.02, d=0.41$, and 
between LA and HANL conditions $(M=2083.70, S D=822.19), p$ $=0.003, d=0.55$, but not between the two high-agency conditions, $p=.79, d=0.11$. There were no differences across conditions in average time spent per mini-game on Round $1, F(2,235)=1.19, p$ $=.31, \eta_{p}{ }^{2}=.01$, or Round $2, F(2,235)=0.77, p=.93, \eta_{p}{ }^{2}=.001$, suggesting that differences in the amount of time spent playing mini-games were driven by the fact that students in the high-agency conditions tended to play fewer mini-games and not that they played individual mini-games more quickly. Analyses were not conducted on Round 3 mini-games, because so few students played extra mini-games $(n=7)$. In general, the LA condition spent significantly more time playing the game than either the HAL or HANL groups.

Deviation from the prescribed path was represented as lengthmatched edit distance, which was calculated as the Levenshtein edit distance [7] between the student's path and a subset of the prescribed path of equal length so as not to over-account for students who played fewer mini-games. This translates to 1 point for each mini-game played out of the prescribed sequence. Oneway ANOVAs indicated a significant difference in length-matched edit distance, $F(2,236)=181.37, p<.001, \eta_{\mathrm{p}}{ }^{2}=.61$. Post hoc (Tukey) tests indicated that there were significant differences between LA $(M=0, S D=0)$ and HAL conditions $(M=5.53, S D=$ $6.82), p<.001$, Glass' $\Delta=0.81$, LA and HANL conditions $(M=$ 14.64, $S D=5.25), p<.001$, Glass' $\Delta=2.79$, and HAL and HANL conditions, $p<.001, d=1.50$. Consistent with expectations, the HAL condition played significantly more mini-games out of sequence than the LA condition but significantly less out of sequence than the HANL.

How does the inclusion of indirect control impact learning and enjoyment? A series of ANOVAs were conducted to determine whether there was an effect of condition on pretest, posttest or delayed test performance (Table 2). There was no effect of condition on pretest performance, $F(2,235)=1.55, p=.21, \eta_{p}{ }^{2}$ $=.01$, indicating that students' prior knowledge did not differ by condition. There was no effect of condition on posttest performance, $F(2,235)=0.77, p=.47, \eta_{p}{ }^{2}=.01$, nor on delayed test performance, $F(2,235)=0.50, p=.61, \eta_{p}{ }^{2}=.004$.

Given that students in the high-agency conditions played on average about 4.5 mini-games fewer and spent less total time playing mini-games, learning efficiency scores were calculated to assess whether students in the high-agency conditions accomplished the same amount of learning in a shorter period of time. As in prior research [23], learning efficiency was calculated for each subject using the z-score of their pre-post or pre-delayed test gains minus the $\mathrm{z}$-score of the total amount of time they spent playing the mini-games (Table 2). One-way ANOVAs indicated significant condition effects on learning efficiency for both posttest, $\mathrm{F}(2,235)=5.73, p=.004, \eta_{p}{ }^{2}=.05$, and delayed posttest, $\mathrm{F}(2,235)=5.04, p=.007, \eta_{p}{ }^{2}=.04$. Post hoc (Tukey) comparisons indicated that the LA condition demonstrated significantly less learning efficiency than both the HAL condition, $p=.012, d=0.45$, and the HANL condition, $p=.011, d=0.41$, but there were no differences between the HAL and HANL conditions, $\mathrm{p}=.95, d=$ 0.05. This indicates that students in the high-agency conditions were able to learn more efficiently than the students in the low agency condition.

Table 2. Test performance and standardized learning efficiency scores by condition.

\begin{tabular}{lrrr}
\hline & \multicolumn{1}{c}{ LA } & \multicolumn{1}{c}{ HAL } & HANL \\
\hline Pretest $M(S D)$ & 39.26 & 35.73 & 38.67 \\
& $(11.48)$ & $(13.24)$ & $(11.66)$ \\
Posttest $M(S D)$ & 43.28 & 41.19 & 43.39 \\
& $(10.83)$ & $(11.66)$ & $(10.25)$ \\
Delayed test $M(S D)$ & 44.49 & 42.44 & 44.04 \\
Pre-post learning & $(10.94)$ & $(12.41)$ & $(9.76)$ \\
efficiency $M(S D)$ & -0.40 & 0.20 & 0.22 \\
Pre-delayed learning & $(1.35)$ & $(1.39)$ & $(1.26)$ \\
efficiency $M(S D)$ & -0.37 & 0.24 & 0.17 \\
& $(1.30)$ & $(1.43)$ & $(1.36)$ \\
\hline
\end{tabular}

To determine whether greater agency led to greater enjoyment of the activity, an ANOVA compared self-reported enjoyment across conditions. Results indicated no effect of agency condition on enjoyment, $F(2,233)=0.30, p=.74$.

How does the exercise of agency in different contexts impact learning and enjoyment? To assess the effects of exercising agency through number of mini-games students played or the order in which students played the mini-games, we focus on students in the high-agency conditions, as they were the only ones with the opportunity to exercise agency. Within the two high-agency conditions, length-matched edit distance was not correlated with pretest performance, $r=.004, p=.95$, posttest performance, $r=$ $.04, p=.49$, or delayed test performance, $r=-.01, p=.85$. Number of mini-games played was significantly, positively correlated with pretest performance, $r=.16, p=.016$, suggesting that those who knew more about decimals at the beginning of the activity also tended to play more mini-games. However, number of mini-games was not correlated with posttest performance, $r=.12, p=.073$, or delayed test performance, $r=.13, p=.053$. Results suggest that the degree to which students exercised agency did not impact test performance.

For assessing the relations between the exercise of agency and enjoyment we again focus on students in the high-agency conditions. Among students in both high-agency conditions, length-matched edit distance was not correlated with enjoyment of the lesson, $r=.09, p=.16$. Number of mini-games played was positively correlated with enjoyment of the lesson, $r=.16, p=.012$.

\section{Discussion}

In this paper we explored the effects of indirect control in the context of digital learning games. We found that students exercise less agency (in the form of deviation from a prescribed path) in the presence of indirect control mechanisms. While there was a difference in the amount of agency exercised there were no significant differences in learning or enjoyment between the conditions, suggesting that indirect control of this kind does not 
Exploring the Subtleties of Agency and Indirect Control in Digital Learning Games

directly impact learning or enjoyment while still influencing the overall learner experience.

Although students in the high-agency conditions did not learn more than students in the low-agency condition, they were able to learn more efficiently by attaining equivalent learning gains in less time. Students were given some regulatory power over their learning, in the sense that they could choose which types of minigames to play and when to quit, and they seem to have successfully self-regulated their learning so that they learned just as much in less time.

Self-regulated learning theory suggests that students are often poor self-regulated learners, and self-regulated learning skills have been hypothesized to mediate relations between agency and learning outcomes $[3,42,43]$. As a result, a common concern in giving students agency is that they will not regulate effectively, either by not studying enough or not studying strategically (e.g., focusing on the wrong problems, completing things in a less than ideal order, etc.). Results from this study are encouraging, in that they show middle school students with moderate prior knowledge (about 60 percent accuracy on average at pretest) made use of the opportunity to regulate their learning and, in doing so, achieved equivalent learning gains in less time compared to those who were not given agency. These results are more likely to generalize to other learning environments where students have some relevant prior knowledge, given that other research has shown students are more effective at planning and monitoring their learning when they have prior domain knowledge [25].

This study builds on both theory and evidence regarding the form and degree of agency offered in a digital learning game. Selfdetermination theory predicts that students will reap the greatest benefits from choice when they are also regulating their own behaviors, including when and how to engage in tasks [29]. In the current study, choice and indirect control over the order of minigames did not seem to lead to any learning differences (i.e., no differences across conditions on learning outcomes or between the two high-agency conditions on learning efficiency), perhaps because choosing the order of mini-games did not lead to any deeper self-regulated behaviors. On the other hand, choosing when to stop playing did seem to impact learning efficiency, and it also more directly related to self-regulation of learning by requiring students to judge whether they had gained enough practice in the mini-games to be prepared for the posttest.

In short, agency did not improve learning, but this study showed that 1) indirect control can be limited to the degree that students actually exercise agency, and 2) students were able to make good choices about exercising agency and ultimately learned more efficiently, suggesting that the game had sufficient support in place to scaffold students' self-regulated learning (an idea discussed by Sawyer et al., [32]).

Some open questions remain from our study. First, it could be argued that students in either of the high agency conditions are likely unaware that they are making a pedagogically consequential choice when they choose a given mini-game. Students were shown a key on the amusement park map that identified the skills
LAK'19, March 2019, Tempe, Arizona USA

addressed by each game (Figure 4); however, it is possible that they were instead focused on selecting levels based on theme, rather than practicing learning content. If this were the case it would amount to an experience similar to the manipulations used in [5, 37] where learners were given control over pedagogically irrelevant components of a game. While a student could have based their sequencing choices on the skills they felt they needed to develop the most and avoided mini-games targeting skills they had already mastered, initial results from students' survey comments about the mini-games and their tendency to play all the mini-games within a given theme suggest that few, if any, were doing so. However, further investigation of students sequencing choices could highlight other patterns driving their decisions and inform why the High Agency conditions were able to achieve greater learning efficiency. This is something we plan to explore in future work.

An alternative interpretation of our results is that Decimal Point simply contains more learning content than it ultimately requires. Given that students in the LA condition were incapable of playing fewer mini-games it is difficult to tell if they would also have achieved similar learning gains in less time as the students in the High Agency conditions have. Looking more closely at students fine-grained learning behaviors through learning curve analyses [14] may allow us to tease apart this issue.

Another potential issue is that while every mini-game in Decimal Point does have dimensions of theme and target skill, they are explicitly linked in the implementation. In future work we could explore severing this link and develop levels capable of being adapted to different themes while still targeting the same skill. Such an implementation could allow for players to exercise agency over theming and navigation through the park while providing an avenue for adaptive sequencing. This could allow us to explore paradigms of shared control over sequencing [19] beyond the strictly game driven or strictly student driven forms that we employed in our study.

An alternative avenue of fostering better self-regulation decisions would be to employ an open learner model [4] to provide students with some representation of skill estimates [20] they could use to inform their choices. This could provide an interesting avenue to not only explore the impact of exposing skill estimates on student learning but also to examine the impact of exposing models of interest estimation on students' exercise of agency. In future work, we plan on exploring just such a question with Decimal Point by creating two versions of the game: one that employs traditional open learner model interface elements [20] and one that captures and reflects players' enjoyment of different types of game levels. Ultimately, we seek to answer whether emphasizing skill attempt or enjoyment will lead to better outcomes.

\section{Conclusion}

This work highlights a subtly of design in digital learning games. In particular, it highlights that it is not merely the provision of choice that matters for driving student agency but also the presentation of that choice. Our results highlight that the context of choice can impact students' ability to make self-determined 
choices. Further, it shows that allowing students choice over their activity sequencing is not necessarily detrimental, as prior work has suggested. Ultimately, further work is needed to better understand the complex relationships between student choice, indirect control, and learning within digital learning games.

\section{ACKNOWLEDGMENTS}

National Science Foundation Award DRL-1238619 funded this research. Thanks to Scott Herbst, Craig Ganoe, Darlan Santana Farias, Rick Henkel, Patrick B. McLaren, Grace Kihumba, Kim Lister, Kevin Dhou, John Choi, and Jimit Bhalani all of whom made important contributions to the design and development of the Decimal Point game.

\section{REFERENCES}

[1] Ainley, M., Hidi, S. and Berndorff, D. 2002. Interest, learning, and the psychological processes that mediate their relationship. Journal of Educational Psychology. 94, 3 (2002), 545-561. DOI:https://doi.org/10.1037/00220663.94.3.545.

[2] Aleven, V., McLaren, B.M. and Sewall, J. 2009. Scaling Up Programming by Demonstration for Intelligent Tutoring Systems Development: An Open-Access Web Site for Middle School Mathematics Learning. IEEE Transactions on Learning Technologies. 2, 2 (Apr. 2009), 64-78. DOI:https://doi.org/10.1109/TLT.2009.22. [3] Azevedo, R. 2015. Defining and Measuring Engagement and Learning in Science: Conceptual, Theoretical, Methodological, and Analytical Issues. Educational Psychologist. 50, 1 (Jan. 2015), 84-94. DOI:https://doi.org/10.1080/00461520.2015.1004069.

[4] Bull, S. and Nghiem, T. 2002. Helping Learners to Understand Themselves with a Learner Model Open to Students, Peers and Instructors. Workshop on Individual and Group Modelling Methods that Help Learners Understand Themselves, International Conference on Intelligent Tutoring Systems. (2002), 5-13.

[5] Cordova, D.I. and Lepper, M.R. 1996. Intrinsic Motivation and the Process of Learning: Beneficial Effects of Contextualization, Personalization, and Choice. Journal of Educational Psychology. 88, 4 (1996), 715-730.

DOI:https://doi.org/10.1037//0022-0663.88.4.715.

[6] d'Ailly, H. 2004. The Role of Choice in Children's Learning: A Distinctive Cultural and Gender Difference in Efficacy, Interest, and Effort. Canadian Journal of Behavioural Science / Revue canadienne des sciences du comportement. 36, 1 (Jan. 2004), 17-29. DOI:https://doi.org/10.1037/h0087212.

[7] Damerau, F.J. 1964. A technique for computer detection and correction of spelling errors. Communications of the ACM. 7, 3 (1964), 171-176. DOI:https://doi.org/10.1145/363958.363994

[8] Deci, E.L., Eghrari, H., Patrick, B.C. and Leone, D.R. 1994. Facilitating Internalization: The Self-Determination Theory Perspective. Journal of Personality 62, 1 (Mar. 1994), 119-142. DOI:https://doi.org/10.1111/j.14676494.1994.tb00797.x. [9] Deterding, S. 2016. Contextual Autonomy Support in Video Game Play: A Grounded Theory. Proceedings of the 2016 CHI Conference on Human Factors in Computing Systems - CHI '16 (New York, New York, USA, 2016), 3931-3943. [10] Flowerday, T. and Schraw, G. 2003. Effect of Choice on Cognitive and Affective Engagement. The Journal of Educational Research. 96, 4 (Mar. 2003), 207-215. DOI:https://doi.org/10.1080/00220670309598810.

[11] Flowerday, T., Schraw, G. and Stevens, J. 2004. The Role of Choice and Interest in Reader Engagement. The Journal of Experimental Education. 72, 2 (Jan. 2004), 93-114. DOI:https://doi.org/10.3200/JEXE.72.2.93-114.

[12] Flowerday, T. and Shell, D.F. 2015. Disentangling the effects of interest and choice on learning, engagement, and attitude. Learning and Individual Differences. 40, February (2015), 134-140. DOI:https://doi.org/10.1016/j.lindif.2015.05.003.

[13] Glass, G. V, Smith, M.L. and McGaw, B. 1981. Meta-analysis in social research. Sage Publications.

[14] Harpstead, E. and Aleven, V. 2015. Using Empirical Learning Curve Analysis to Inform Design in an Educational Game. Proceedings of the 2015 Annual Symposium on Computer-Human Interaction in Play - CHI PLAY'15 (New York, New York, USA, 2015), 197-207.

[15] Hasler, B.S., Kersten, B. and Sweller, J. 2007. Learner control, cognitive load and instructional animation. Applied Cognitive Psychology. 21, 6 (Sep. 2007), 713729. DOI:https://doi.org/10.1002/acp.1345.

[16] Hoaglin, D.C. and Iglewicz, B. 1987. Fine-Tuning Some Resistant Rules for Outlier Labeling. Journal of the American Statistical Association. 82, 400 (Dec. 1987), 1147-1149. DOI:https://doi.org/10.1080/01621459.1987.10478551. [17] Kirschner, P.A., Sweller, J. and Clark, R.E. 2006. Why Minimal Guidance During Instruction Does Not Work: An Analysis of the Failure of Constructivist,
Discovery, Problem-Based, Experiential, and Inquiry-Based Teaching. Educational Psychologist. 41, 2 (2006), 75-86.

[18] Lehman, J. et al. 2018. The Surprising Creativity of Digital Evolution: A Collection of Anecdotes from the Evolutionary Computation and Artificial Life Research Communities. (2018), 1-32.

[19] Long, Y. and Aleven, V. 2014. Gamification of Joint Student/System Control over Problem Selection in a Linear Equation Tutor. Intelligent Tutoring Systems. Springer. 378-387.

[20] Malacria, S., Scarr, J., Cockburn, A., Gutwin, C. and Grossman, T. 2013. Skillometers: Reflective Widgets that Motivate and Help Users to Improve Performance. Proceedings of the 26th annual ACM symposium on User interface software and technology - UIST '13 (New York, New York, USA, 2013), 321-330. [21] McLaren, B., Farzan, R., Adams, D., Mayer, R. and Forlizzi, J. 2017.

Uncovering Gender and Problem Difficulty Effects in Learning with an Educational Game. Lecture Notes in Computer Science (including subseries Lecture Notes in Artificial Intelligence and Lecture Notes in Bioinformatics). E. André, R. Baker, X. Hu, M.M.T. Rodrigo, and B. du Boulay, eds. Springer International Publishing. 540543

[22] McLaren, B.M., Adams, D.M., Mayer, R.E. and Forlizzi, J. 2017. A ComputerBased Game that Promotes Mathematics Learning More than a Conventional Approach. International Journal of Game-Based Learning. 7, 1 (Jan. 2017), 36-56. DOI:https://doi.org/10.4018/IJGBL.2017010103.

[23] McLaren, B.M., Lim, S. and Koedinger, K.R. 2008. When and how often should worked examples be given to students? New results and a summary of the current state of research. Proceedings of the 30th annual Conference of the Cognitive Science Society. (2008), 2176-2181.

[24] Metcalfe, J. and Kornell, N. 2003. The Dynamics of Learning and Allocation of Study Time to a Region of Proximal Learning. Journal of Experimental Psychology: General. 132, 4 (2003), 530-542. DOI:https://doi.org/10.1037/0096-3445.132.4.530. [25] Moos, D.C. and Azevedo, R. 2008. Self-regulated learning with hypermedia: The role of prior domain knowledge. Contemporary Educational Psychology. 33, 2 (Apr. 2008), 270-298. DOI:https://doi.org/10.1016/j.cedpsych.2007.03.001. [26] Nguyen, H., Harpstead, E., Wang, Y. and McLaren, B.M. 2018. Student Agency and Game-Based Learning: A Study Comparing Low and High Agency. Proceedings of Artificial Intelligence in Education - AIED 2018 (Cham, 2018), 338351.

[27] Patall, E.A., Cooper, H. and Robinson, J.C. 2008. The Effects of Choice on Intrinsic Motivation and Related Outcomes: A Meta-Analysis of Research Findings. Psychological Bulletin. 134, 2 (2008), 270-300. DOI:https://doi.org/10.1037/00332909.134.2.270.

[28] Patel, R., Liu, R. and Koedinger, K. 2016. When to block versus interleave practice? Evidence against teaching fraction addition before fraction multiplication. Proceedings of the 38th Annual Conference of the Cognitive Science Society. (2016), 2069-2074.

[29] Reeve, J., Nix, G. and Hamm, D. 2003. Testing models of the experience of self-determination in intrinsic motivation and the conundrum of choice. Journal of Educational Psychology. 95, 2 (2003), 375-392. DOI:https://doi.org/10.1037/00220663.95.2.375.

[30] Rohrer, D., Dedrick, R.F. and Burgess, K. 2014. The benefit of interleaved mathematics practice is not limited to superficially similar kinds of problems. Psychonomic Bulletin \& Review. 21, 5 (Oct. 2014), 1323-1330. DOI:https://doi.org/10.3758/s13423-014-0588-3.

[31] Ryan, R.M., Rigby, C.S. and Przybylski, A. 2006. The Motivational Pull of Video Games: A Self-Determination Theory Approach. Motivation and Emotion. 30 , 4 (Nov. 2006), 344-360. DOI:https://doi.org/10.1007/s11031-006-9051-8. [32] Sawyer, R., Smith, A., Rowe, J., Azevedo, R. and Lester, J. 2017. Is more agency better? The impact of student agency on game-based learning. Lecture Notes in Computer Science (including subseries Lecture Notes in Artificial Intelligence and Lecture Notes in Bioinformatics). 10331 LNAI, (2017), 335-346.

DOI:https://doi.org/10.1007/978-3-319-61425-0_28.

[33] Schell, J. 2008. Story and Game Structures Can be Artfully Merged with Indirect Control. The Art of Game Design: A Book of Lenses. Taylor \& Francis. 317 334.

[34] Schell, J. 2005. Understanding entertainment. Computers in Entertainment. 3, 1 (Jan. 2005), 6. DOI:https://doi.org/10.1145/1057270.1057284

[35] Schneider, S., Nebel, S., Beege, M. and Rey, G.D. 2018. The autonomyenhancing effects of choice on cognitive load, motivation and learning with digital media. Learning and Instruction. 58, January (Dec. 2018), 161-172. DOI:https://doi.org/10.1016/j.learninstruc.2018.06.006.

[36] Schneider, W. and Lockl, K. The development of metacognitive knowledge in children and adolescents. Applied Metacognition. T.J. Perfect and B.L. Schwartz, eds. Cambridge University Press. 224-258.

[37] Snow, E.L., Allen, L.K., Jacovina, M.E. and McNamara, D.S. 2015. Does agency matter?: Exploring the impact of controlled behaviors within a game-based environment. Computers and Education. 82, (2015), 378-392.

DOI:https://doi.org/10.1016/j.compedu.2014.12.011.

[38] Stacey, K., Helme, S. and Steinle, V. 2001. Confusions between decimals, fractions and negative numbers: A consequence of the mirror as a conceptual 
Exploring the Subtleties of Agency and Indirect Control in Digital Learning Games

metaphor in three different ways. Proceedings of the 25th Conference of the

International Group for the Psychology of Mathematics Education (Utrectcht, 2001),

217-224.

[39] Sweller, J. 1994. Cognitive Load Theory, Learning Difficulty, And Instructional Design. Learning and Instruction. 4, (1994), 295-312.

[40] Vandewaetere, M. and Clarebout, G. 2013. Cognitive Load of Learner Control: Extraneous or Germane Load? Education Research International. 2013, 2013 (2013), 1-11. DOI:https://doi.org/10.1155/2013/902809.

[41] Wardrip-Fruin, N., Mateas, M., Dow, S. and Sali, S. 2009. Agency

Reconsidered. Proceedings of DiGRA 2009 (2009).

[42] Winne, P.H. 1995. Inherent details in self-regulated learning. Educational

Psychologist. 30, 4 (Sep. 1995), 173-187.

DOI:https://doi.org/10.1207/s15326985ep30042.

[43] Zimmerman, B.J. 2001. Theories of Self-Regulated Learning and Academic

Achievement: An Overview and Anaysis. Self-Regulated Learning and Academic Achievement: Theoretical Perspectives. B.J. Zimmerman and D.H. Schunk, eds.

Routledge. 